\title{
Common and distinct cognitive bases for reading in English-Cantonese bilinguals
}

\section{Citation}

LUK, GIGI, and ELLEN BIALYSTOK. 2008. "Common and distinct cognitive bases for reading in English-Cantonese bilinguals." Applied Psycholinguistics 29 (02) (April 29). doi:10.1017/ S0142716407080125. http://dx.doi.org/10.1017/S0142716407080125.

\section{Published Version}

doi:10.1017/S0142716407080125

\section{Permanent link}

http://nrs.harvard.edu/urn-3:HUL.InstRepos:11384943

\section{Terms of Use}

This article was downloaded from Harvard University's DASH repository, and is made available under the terms and conditions applicable to Other Posted Material, as set forth at http:// nrs.harvard.edu/urn-3:HUL.InstRepos:dash.current.terms-of-use\#LAA

\section{Share Your Story}

The Harvard community has made this article openly available.

Please share how this access benefits you. Submit a story.

\section{Accessibility}




\title{
Common and distinct cognitive bases for reading in English-Cantonese bilinguals
}

\author{
GIGI LUK and ELLEN BIALYSTOK \\ York University
}

Received: December 15, 2006 Accepted for publication: July 10, 2007

\author{
ADDRESS FOR CORRESPONDENCE \\ Ellen Bialystok, Department of Psychology, York University, 4700 Keele Street, Toronto, Ontario \\ M3J 1P3, Canada. E-mail: ellenb@yorku.ca
}

\begin{abstract}
The study explores the relationship between phonological awareness and early reading for bilingual children learning to read in two languages that use different writing systems. Participants were 57 Cantonese-English bilingual 6-year-olds who were learning to read in both languages. The children completed cognitive measures, phonological awareness tasks, and word identification tests in both languages. Once cognitive abilities had been controlled, there was no correlation in word identification ability performance across languages, but the correspondence in phonological awareness measures remained strong. This pattern was confirmed by a principal components analysis and hierarchical regression that demonstrated a different role for each phonological awareness factor in reading performance in each language. The results indicate that phonological awareness depends on a set of cognitive abilities that is applied generally across languages and that early reading depends on a common set of cognitive abilities in conjunction with skills specific to different writing systems.
\end{abstract}

The correlation between the development of phonological awareness and alphabetic literacy is uncontroversial (e.g., Goswami \& Bryant, 1990; Muter \& Snowling, 1998; Passenger, Stuart, \& Terrell, 2000; Savage \& Stuart, 2001; Wagner \& McBride-Chang, 1996), and stronger claims for a causal relationship between them have also been substantiated (Cormier \& Dea, 1997; Kirby, Parrila, \& Pfeiffer, 2003; Rohl \& Pratt, 1995). It is not surprising that competence with the detection and manipulation of phonemes is fundamental to learning to read in a system in which oral language is mapped onto writing through phonemic units. However, not all writing systems work on that principle: writing systems can record spoken language at the level of phonemes, syllables, or morphemes (Coulmas, 1989), and in each case, the acquisition of reading may be based on different linguistic, metalinguistic, and domain-general cognitive abilities. The relationship between phonological awareness and learning to read, therefore, is not necessarily universal across writing systems. A divergence in the relationship between these two skills 
for different writing systems would signal fundamental differences between them that would have implications for development and instruction.

At some level, reading in any writing system requires phonological analysis because print records spoken language (Perfetti, 2003). This relationship between phonological analysis and reading is most apparent at the level of word identification, or word-level reading. Understanding the specific relationship between oral and written systems is important for determining the cognitive basis for reading and phonological awareness: are they based on a common set of cognitive and metalinguistic abilities that develop through maturation and experience, or does reading in different systems invoke specialized abilities with different developmental trajectories? The answers to these questions have implications for whether instruction aimed at one language can be expected to affect performance in the other, and whether similar approaches to reading instruction are possible. At issue is the problem of characterizing literacy in relation to other nonlinguistic cognitive skills and the phonological awareness measures with which it is so closely aligned.

One difficulty in addressing this question is that the relationship between phonological awareness and reading may overlap with other variables that are also crucial to learning to read. For example, early literacy ability has been statistically related to vocabulary level (e.g., Foy \& Mann, 2001; Gathercole, Willis, Emslie, \& Baddeley, 1992; Metsala, 1999; Nation \& Snowling, 2004) and, less directly, to working memory (e.g., Cain, Oakhill, \& Bryant, 2004; Swanson, Sáez, Gerber, $\&$ Leafstedt, 2004). In one study, working memory correlated with reading comprehension but not word-level decoding (Oakhill, Cain, \& Bryant, 2003), but other studies have shown an indirect relationship between working memory and vocabulary development (Gathercole \& Baddeley, 1989; Oakhill \& Kyle, 2000), an area that is directly connected to decoding. It is possible that different levels of reading require different components of working memory; for example, wordlevel decoding may require short-term verbal memory, whereas comprehension may require the involvement of executive processes. In fact, working memory as a cognitive construct may be the common association between literacy, phonological awareness, and vocabulary. Significant relationships have also been reported between decoding ability and nonverbal reasoning skills for children learning to read (Huang \& Hanley, 1995). Therefore, these cognitive factors need to be considered in an examination of the relationship between phonological awareness and learning to read.

Most of the research examining the cognitive and metalinguistic foundations of literacy has been conducted with children learning to read in English, but some research has explored other languages as well. Most interesting is the case of Chinese, where the writing system is completely different from our familiar alphabetic system. Chinese is represented in a morphosyllabic script (Coulmas, 1989; DeFrancis, 1989) in which approximately $80 \%$ of the characters are combinations of semantic components (radicals) and phonetic components (phonics) (Hanley, Tzeng, \& Huang, 1999). Huang and Hanley (1995) reported a significant relationship between Chinese reading and visual working memory. However, other research has found that phonological memory, not visual memory, was related to Chinese character identification, even after age and vocabulary were controlled, both for Mandarin (Hu \& Catts, 1998) and Cantonese (McBride-Chang \& Ho, 
2000). Some studies have also found significant correlations between nonverbal reasoning skills and learning to read in Chinese-speaking children (Ho \& Bryant, 1997a; Huang \& Hanley, 1995; Siok \& Fletcher, 2001). Using functional magnetic resonance imaging (fMRI), it was further shown that the cortical basis of dyslexia is different for Chinese-reading children than for English-reading children (Siok, Perfetti, Jin, \& Tan, 2004). Therefore, the role of cognitive variables in reading for other writing systems is not necessarily the same as it is in alphabetic languages in general or English in particular.

A general explanation for the relationship between skills involved in phonological awareness and reading would need to apply to all languages, but crosslanguage comparisons carry confounds that can be traced to the specific features of the language or writing system, as indicated above. Therefore, the clearest test of the relationship between early reading and other cognitive and phonological awareness skills comes from the study of bilingual children learning to read in two writing systems who are approaching the task with a single set of cognitive resources. This control over individual differences enables more valid comparison across languages.

Such bilingual studies have generally found a correlation between phonological awareness abilities in the two languages (Durgunoğlu, Nagy, \& Hancin-Bhatt, 1993; Gomez \& Reason, 2002), even when the languages were represented by different writing systems (Gottardo, Siegel, Yan, \& Wade-Woolley, 2001; Wang, Park, \& Lee, 2006; Wang, Perfetti, \& Liu, 2005). In contrast, a stable and strong cross-language correlation in reading ability occurs less reliably, but is found if the languages are represented by the same writing system (Bialystok, Luk, \& Kwan, 2005; Geva \& Siegel, 2000; Gholamain \& Geva, 1999; Swanson et al., 2004; Wade-Woolley \& Geva, 2000). Cross-language correlation in word identification is not as clear if the languages use different writing systems. Some studies have reported no correlation across languages (Bialystok, Luk, et al., 2005; Bialystok, McBride-Chang, \& Luk, 2005; Gottardo et al., 2001; Wang et al., 2005), although others have found a positive correlation (Wang, Cheng, \& Chen, 2006; Wang et al., 2006). As indicated above, reading in different languages requires different levels of general cognitive skills. Therefore, the apparently contradictory results obtained from these studies may reflect differences in initial levels of cognitive abilities relevant to reading in each of the languages, a factor not controlled in any of these studies. To examine unbiased relationships in cross-linguistic language processing it is important to take into account individual differences in general cognitive skills. Without such a control, it is uncertain whether the cross-language correlations in word reading reported reflect covariance in nonlinguistic cognitive measures and word identification process or simply word identification process alone.

As noted above, the type of writing system appears to influence the relation between cross-language skills for reading but not for phonological awareness, modifying by implication the relation between phonological awareness and reading. It is not surprising that the usual relationship between reading and phonological awareness found for alphabetic languages does not hold for other writing systems; indeed, the surprising result was that there actually was a correspondence between phonological awareness and Chinese reading, as described below. The important point, rather, is to establish the cognitive basis of phonological awareness and 
Luk \& Bialystok: Phonological awareness and word identification

reading so that the extent to which children can generalize these skills and apply them to new languages can be understood more clearly. Such an analysis will contribute to an understanding of how these abilities are related in a broader conception of cognitive performance and cognitive development.

The relationship between reading and phonological awareness changes with the phonological unit most relevant for the specific writing system: syllables are important for character systems, onset-rime units are required for syllabaries, and phonemes are necessary for alphabetic systems. These levels are assessed by different tasks and have different roles in reading (McBride-Chang, Bialystok, Chong, \& Li, 2004), but they have been shown to be represented by a single underlying structure (Anthony \& Lonigan, 2004; Branum-Martin et al., 2006; Schatchneider, Francis, Foorman, Fletcher, \& Mehta, 1999). These results suggest that there is coherence to the notion of phonological awareness, even though reading may be a less general construct.

A growing body of research has found a significant relationship between phonological awareness and Chinese reading (Chan \& Siegel, 2001; Ho \& Bryant, 1997b; Hu \& Catts, 1998; McBride-Chang \& Ho, 2000; McBride-Chang \& Kail, 2002), although contrary results have also been reported (Huang \& Hanley, 1995). Different relationships with phonological awareness have even been found for different types of Chinese characters: Ho and Bryant (1997a) found that rhyme detection was correlated with reading performance in both ideophonetic compounds that contain more than one pronounceable component and pseudocharacters where the pronunciation is not obvious, but not for standard Chinese characters that have been learned holistically. It appears that some analysis is required to partition and read the ideophonetic compounds and the phonetic compartment in the ambiguous pseudocharacters, a process that may resemble alphabetic reading, but the learned standard characters may bypass such processing because they are memorized wholes. It would be interesting to establish whether early alphabetic words learned as recognized patterns were also exempt from the usual relationship between phonological awareness and early reading. In principle, however, the relationship between phonological awareness in general, and rhyme in particular, to Chinese reading is more varied than it is for alphabetic reading in English.

English and Chinese also differ in that the latter is a tonal language, and Cantonese in particular includes a large number of tonal distinctions. Two characters with the same phonemic composition can endorse different meaning: in Cantonese, for example, maa(1) means "mother" and maa(5) means "horse," the number indicating the level and contour of tones. The ability to discriminate tones is similar to phonological awareness but based on different attentional procedures. Wayland and Guion (2004) showed that native Chinese speakers were more successful at discriminating between Thai tones than their native English peers both before and after training. The authors conclude that tone perception, like other levels of phonological awareness, can be generalized from one language to another.

The present study extends previous research on the relationship between phonological awareness and reading across languages for bilingual children by including assessments of working memory and cognitive ability. The participants are Cantonese-English bilingual children who are learning to read in both 
languages. The central hypothesis is that cross-language phonological awareness and word identification in young bilingual children represent two types of processing; specifically, phonological awareness is based on general linguistic abilities that can be applied to any stimuli irrespective of language, whereas word identification is based on skills that are specific to the demands of different writing systems. The assumption is that these relationships are only evident once the variance associated with nonlinguistic cognitive performance common to all these tasks has been removed. Therefore, the results are expected to show that phonological awareness ability will generalize across languages and be governed by levels of cognitive development. On the other hand, consistent with previous research, reading ability will depend on the experience with that writing system (Bialystok, McBride-Chang, et al., 2005; McBride-Chang et al., 2004).

\section{METHOD}

\section{Participants}

Fifty-seven Cantonese-English bilingual children (26 girls, 31 boys), 6 years old $(M=76.34, S D=3.47)$ who were in first grade were recruited from two public elementary schools in a large multicultural city. The participants were born in Canada, but their parents or grandparents were immigrants from Hong Kong, and Cantonese was the language of the home. The children attended local public schools where all the instruction was in English. In addition, the children attended weekly heritage language classes where they were taught Cantonese formally and were learning to read in Cantonese. Although their reading instruction in both English and Chinese was in the early stages, they have received considerably more training in English (daily) than in Chinese (weekly). The bilingualism of the children was assessed during the first meeting through casual conversation in both languages with the bilingual experimenter about such topics as favorite foods, movies, and books. Children who were unable to participate in these conversations because of linguistic limitations were excluded from the study.

A questionnaire assessing children's home language environment was given to the parents with the permission form. The forms were printed in both English and Cantonese. Parents were asked to indicate the home language usage on a scale of 1-5 ( $1=$ all Cantonese and $5=$ all English $)$, with the intervening scores representing degrees of balance. The mean scores were $2.98(S D=0.83)$ and $2.14(S D=0.81)$ for the children and the adults respectively, indicating a slightly greater use of Cantonese by the adults. The $t$ tests comparing the scores against a hypothesis of 3 (i.e., half English and half Cantonese) showed that the children's score was not significantly different from $3, t(55)=-0.14, n s$, but the adults' score indicated a bias for using Cantonese, $t(55)=8.01, p<.0001$. This pattern confirms the bilingual status of the children in the study.

Because Cantonese is a tonal dialect without formal written representation, it is based on Mandarin writing. The textbooks in the programs that the children were attending came from Hong Kong, where Cantonese is the dominant language. Because there is only a loose relationship between the spoken and written languages, Cantonese reading instruction proceeds by memorization of 
Luk \& Bialystok: Phonological awareness and word identification

characters with teachers explaining the meaning and meaning components of each character. There is no phonological analysis of the characters in the instruction.

Tasks

Peabody Picture Vocabulary Test-Third Edition (PPVT-III). In this test (Dunn \& Dunn, 1997) of receptive vocabulary, plates containing four pictures are shown to the child and the experimenter names one of the pictures. The child is required to point to the named picture, and testing terminates when the child is incorrect on 8 out of 12 items in a set. The sets contain items with increasing difficulty level. Both Form A and Form B of the PPVT-III were translated into Cantonese by two native Cantonese speakers from previous studies (Bialystok, McBride-Chang, et al., 2005; McBride-Chang et al., 2004). Half of the children were given the English Form A and Cantonese Form B and the other half was given Cantonese Form A and English Form B. Raw scores are obtained by subtracting the number of incorrect responses from the last item administered, and are then converted to standard scores by means of normed tabled based on the child's age. All analyses were conducted on the standard scores. The reported internal consistency reliability measure for the English PPVT-III for children of this age is .93. The calculated Cronbach $\alpha$ for the Cantonese PPVT in this particular sample is .96.

Raven's Coloured Matrices. Children's nonverbal analytic reasoning was measured by the Raven's Coloured Progressive Matrices (Raven, 1998). The child was asked to choose which of six pictures best fits the missing piece in a larger geometric figure. There are three sets of 12 problems each, and difficulty increases progressively through the task. The score is the total number of items that are solved correctly, to a maximum of 36 . The reported split-half reliability scores for this task is at least .90 depending on the age and ethnicity of the participants.

Sequencing span. Verbal working memory was measured by an adaptation of the sequencing span task (Bialystok, Craik, Klein, \& Viswanathan, 2004). In the present version, the experimenter presented a string of single-digit numbers and children were required to repeat the digits back in ascending order. There were two trials at every string length. The test began with a string of two single-digit numbers and increased by one number after every two trials. Testing continued for two string lengths beyond the point at which the child failed to report both trials correctly. One point was given to a correct digit that was placed in the correct order. This task was only administered in English. The Cronbach $\alpha$ for this task was .56.

English and Chinese syllable deletion. The experimenter asked the child to repeat each item and then to delete one syllable from either the onset, medial, or final position of a three-syllable pseudoword. For example, in the English task, the child was asked to say "imbulate" without "bu," so the answer would be "imlate." In the Chinese version, real characters were put together to form "pseudowords" that do not normally combine and do not contain semantic information. These nonwords could not actually be written, but because the task was administered orally, it did 
not matter. There were 10 items in each of the English and Cantonese versions of the task, consisting of two or three items for every position deletion. The task is based on one used in a previous study with a larger sample size in which the reported reliabilities (Cronbach $\alpha$ ) were .83 and .84 for the English and Chinese versions, respectively (McBride-Chang et al., 2004). The calculated Cronbach $\alpha$ s for this particular sample were .42 and .66 for the English and Chinese versions, respectively. Because there were only two or three items for each deletion position, there is not sufficient data to calculate reliabilities separately for these items.

English and Chinese phoneme onset deletion. Each child was asked to delete a phoneme from the onset position of 10 pseudowords. As in the syllable deletion task, the procedure resulted in another pseudoword (e.g., say "tong" without the first /t/ sound). A similar task was administered in Cantonese with a real character; for example, say si(1) without the first sound; (1) indicates the tone of the syllable. The resulting sound was a syllable with the same rime and tone as the stimulus. Although the resulting syllable was not a pseudocharacter, the syllables did not contain semantic information by themselves. In fact, the resulting syllables were supporting phonetics that do not represent any tangible objects. The Cronbach $\alpha$ reliability measures for the phoneme onset deletion tasks were .81 and .87 for the English and Chinese versions, respectively.

English phoneme counting. This task was used to detect the child's awareness of the smallest contrastive sound unit of spoken English. The experimenter presented a word and the child was asked to segment the word into phonemes and tell the experimenter how many sounds there were. The concept of phoneme is more salient in English than in Chinese because of the differences in writing systems, and for this reason, children are never taught to segment a Chinese character into the level of phonemes. A small sample of adult native speakers of Cantonese was asked to solve these phoneme counting items in Chinese, but none of them succeeded. Therefore, a parallel task for this concept was not created for Cantonese. The Cronbach $\alpha$ reliability measure for the English phoneme counting task, based on a larger sample size in a previous study, was .76 (Bialystok, McBride, et al., 2005). For the present sample, the Cronbach $\alpha$ was .52.

Tone awareness. Cantonese is a tonal language — words with the same phoneme combination but different tones are written with different characters and have different meanings. In a global sense, sensitivity to tones in Chinese is analogous to sensitivity to phonemes in English. Children were given 10 pair of characters that had the same combinations of phonemes but composed of different tones. Then, they were asked to judge whether the two characters "sound" the same or different. Three training trials were presented before the 10 experimental items. The reliability score for this task is .40 . This reliability is only moderate, but there is no other known measure for sensitivity to tone, and it seemed a potentially relevant skill for Chinese reading. A possible explanation for the low reliability is that Cantonese tone is not an independent phonological construct. It binds phonology and semantics and is deeply related to both of these linguistic structures. Moreover, the tones in Cantonese overlap with each other and do not represent 
Luk \& Bialystok: Phonological awareness and word identification

distinct dimensions. Therefore, the low reliability of Cantonese tonal awareness reflects the complex linguistic structure of tone that is unique in Cantonese.

English word identification. The R's word identification subtest of the Woodcock Reading Mastery Test (Woodcock \& Johnson, 1987) was used. Children read aloud a series of words until they made six consecutive errors in the last six items of a set. Raw scores were used in subsequent data analysis. The reported split-half reliability score for Grade 1 children was .98 .

Chinese character identification. A list of 25 Chinese simple characters that children were likely to encounter when they first learn to read Chinese was presented to the children. The list has been used in previous studies for children from both Hong Kong and Canada (Ho \& Bryant, 1997b; McBride-Chang et al., 2004). Twenty-three of these characters were holistic and two were phonetic compounds. These two phonetic compounds were administered at the end of the task and all the children were instructed to read aloud all the characters presented. Because the teaching curriculum of the Chinese programs was not standardized, variability of children's Chinese reading level was expected. The Cronbach $\alpha$ reliability measure for this list of character was .92 .

\section{Procedure}

Each child participated in two testing sessions, one conducted in each language. The order of language sessions and PPVT-III forms was counterbalanced, yielding four combinations: (a) English first with PPVT-III Form A in English; (b) English first with PPVT-III Form B in English; (c) Cantonese first with PPVT-III Form A in Cantonese; and (d) Cantonese first with PPVT-III Form B in Cantonese. In the English session, tasks were presented in the following order: PPVT-III, syllable deletion, phoneme onset deletion, word identification, sequencing span, and phoneme counting. In the Cantonese session, tasks were presented as follows: Raven's Matrices, PPVT-III, syllable deletion, phoneme onset deletion, character identification, and tone awareness. Each session lasted approximately $25 \mathrm{~min}$. All testing was done in a quiet place in the child's school. To maintain motivation, a small sticker was given to the child after every two tasks and a larger square sticker at the end of each session.

\section{RESULTS}

\section{Descriptive statistics}

Scores for the language tasks are reported in Table 1. A dependent $t$ test showed that children's vocabulary score on the PPVT-III was higher in English than in Cantonese, $t(56)=3.89, p<.001$. A two-way analysis of variance for language (2) and syllable position (3) for the syllable deletion tasks showed a significant language by position interaction, $F(2,112)=3.46, p<.04$. In English, the position effect was modest, $F(2,112)=3.01, p=.05$, and contrasts showed that children correctly deleted more syllables in the final position than the onset position, 
Luk \& Bialystok: Phonological awareness and word identification

Table 1. Mean score and standard deviation on vocabulary and phonological awareness tasks

\begin{tabular}{|c|c|c|c|}
\hline \multirow[b]{2}{*}{ Variables } & \multirow[b]{2}{*}{ Maximum } & \multicolumn{2}{|c|}{ Mean Scores $(S D)$} \\
\hline & & English & Chinese \\
\hline \multicolumn{4}{|l|}{ PPVT } \\
\hline Raw & 204 & $79.86(17.68)$ & $66.47(23.35)$ \\
\hline Standard $^{a}$ & - & $95.28(13.78)$ & $83.98(18.36)$ \\
\hline \multicolumn{4}{|l|}{ Syllable deletion } \\
\hline Onset $^{b}$ & 1 & $0.62(0.36)$ & $0.81(0.30)$ \\
\hline Medial $^{b}$ & 1 & $0.68(0.30)$ & $0.69(0.35)$ \\
\hline Final $^{b}$ & 1 & $0.76(0.26)$ & $0.90(0.21)$ \\
\hline \multicolumn{4}{|l|}{ Phoneme } \\
\hline Onset deletion & 10 & $7.42(2.67)$ & $7.18(3.09)$ \\
\hline Counting & 10 & $5.82(1.86)$ & - \\
\hline Tone awareness & 10 & - & $8.23(1.39)$ \\
\hline Word identification & $106 / 25^{c}$ & $37.63(19.06)$ & $14.40(6.65)$ \\
\hline
\end{tabular}

${ }^{a}$ Peabody Picture Vocabulary Test (PPVT) standard scores are standardized to control for age. For subsequent analyses, standard scores of the English and Chinese PPVTs were used.

${ }^{b}$ Proportion scores are reported for the syllable deletion tasks for each position.

${ }^{c}$ The English reading test has 106 items total and the Chinese reading test has 25 items.

$F(1,56)=5.9, p<.02$, with the medial position not different from either of these. In Chinese, there was a strong effect of syllable position, $F(2,112)=9.18$, $p<.0001$, with all pairwise contrasts significant, $F \mathrm{~s}(1,56)>4.17, p \mathrm{~s}<.05$, showing that final position deletions were the easiest and medial positions the most difficult. There was no difference between the two languages for phoneme onset deletion $(t<1)$.

Although no direct comparison can be made between the two reading scores because the tests were constructed on different scales, it is possible to compare performance on them more indirectly. The Woodcock-Johnson Word Identification Test has 106 items and is standardized to test population ranging from children to adults; the Chinese character list has 25 items and is designed for children learning to read. Therefore, a relative proportion was calculated for each of the reading tasks. For the Chinese reading tasks, the total number of items (25) was used as the denominator and for the English word identification task, the highest performance in the task for this sample (70) was considered as the denominator. The proportion scores (and standard deviations), were .53 (.27) and .57 (.27) for English and Chinese reading tasks, respectively. These scores were not significantly different from each other, $t(56)=-1.9, n s$.

The mean score (standard deviation) out of 36 on the Raven's Progressive Matrices was 22.9 (4.2) and the mean score on the sequencing span test of working memory was 16.7 (8.5). These variables were used in the analyses to examine the 
Luk \& Bialystok: Phonological awareness and word identification

Table 2. Intercorrelations of cognitive tasks, language tasks, and word identification scores for each language

\begin{tabular}{|c|c|c|c|c|c|c|c|c|}
\hline Task & 2 & 3 & 4 & 5 & 6 & 7 & 8 & 9 \\
\hline \multicolumn{9}{|c|}{ English Tasks } \\
\hline $\begin{array}{l}\text { 1. PPVT (std.) } \\
\text { 2. Syllable deletion, onset } \\
\text { 3. Syllable deletion, medial } \\
\text { 4. Syllable deletion, final } \\
\text { 5. Phoneme onset deletion } \\
\text { 6. Phoneme counting } \\
\text { 7. Raven's Matrices } \\
\text { 8. Working memory } \\
\text { 9. Word identification }\end{array}$ & $\begin{array}{c}-.03 \\
-\end{array}$ & $\begin{array}{l}.24 \\
.05 \\
-\end{array}$ & $\begin{array}{r}-.22 \\
.05 \\
-.04 \\
-\end{array}$ & $\begin{array}{l}.46^{* *} \\
.24 \\
.29 \\
.14 \\
-\end{array}$ & $\begin{array}{c}.14 \\
.43^{* *} \\
.12 \\
-.03 \\
.40^{* *} \\
-\end{array}$ & $\begin{array}{l}.14 \\
.26 \\
.08 \\
.05 \\
.41^{* *} \\
.11 \\
-\end{array}$ & $\begin{array}{l}.35^{* *} \\
.00 \\
.09 \\
.20 \\
.47^{* *} \\
.00 \\
.25 \\
-\end{array}$ & $\begin{array}{l}.46^{* *} \\
.36^{* *} \\
.30 \\
-.15 \\
.70^{* *} \\
.41^{* *} \\
.41^{* *} \\
.44^{* *} \\
-\end{array}$ \\
\hline \multicolumn{9}{|c|}{ Chinese Tasks } \\
\hline $\begin{array}{l}\text { 1. PPVT (std.) } \\
\text { 2. Syllable deletion, onset } \\
\text { 3. Syllable deletion, medial } \\
\text { 4. Syllable deletion, final } \\
\text { 5. Phoneme onset deletion } \\
\text { 6. Tone awareness } \\
\text { 7. Raven's Matrices } \\
\text { 8. Working memory } \\
\text { 9. Word identification }\end{array}$ & $\begin{array}{l}.31 \\
-\end{array}$ & $\begin{array}{l}.27 \\
.22 \\
-\end{array}$ & $\begin{array}{l}.21 \\
.24 \\
.15 \\
-\end{array}$ & $\begin{array}{l}.11 \\
.21 \\
.41^{* *} \\
.25 \\
-\end{array}$ & $\begin{array}{l}.15 \\
.21 \\
.31 \\
.13 \\
.29 \\
-\end{array}$ & $\begin{array}{l}.23 \\
.25 \\
.26 \\
.19 \\
.27 \\
.42^{* *} \\
-\end{array}$ & $\begin{array}{l}.11 \\
.29 \\
.25 \\
.25 \\
.46^{* *} \\
.28 \\
.25 \\
-\end{array}$ & $\begin{array}{l}.35^{* *} \\
.33 \\
.16 \\
-.04 \\
.27 \\
.19 \\
.37^{* *} \\
.21 \\
-\end{array}$ \\
\hline
\end{tabular}

Note: PPVT, Peabody Picture Vocabulary Test.

$* * p<.01$.

relationships among the language tasks and the variables associated with reading in each language reported in the following sections.

\section{Within-language and between-language correlations}

The correlations among the tasks in each language, shown in Table 2, indicate different patterns for English and Chinese. In English, word reading was related to all the cognitive and linguistic measures, except for syllable deletion in the medial and final positions; in Chinese, reading was related only to receptive vocabulary and Raven's Matrices $(r \mathrm{~s}>.35, p \mathrm{~s}<.01)$ and none of the phonological measures. The lack of correlation between Chinese word identification and phonological measures replicates previous research on Canadian English-Cantonese bilinguals (Bialystok, McBride-Chang, et al., 2005). Relations among phonological awareness tasks were also different: English phoneme onset deletion was correlated with receptive vocabulary, Raven's Matrices, and working memory ( $r \mathrm{~s}>.41, p<$ $.01)$; Chinese phoneme onset deletion was correlated with working memory, and 
Luk \& Bialystok: Phonological awareness and word identification

tone awareness was correlated with Raven's Matrices $(r \mathrm{~s}>.42, p<.01)$. These results indicate a stronger association between the abilities required for English reading and the cognitive and linguistic skills assessed in the other tasks than for Chinese reading and these abilities, where the association was at the broad level of fluid intelligence (Raven's Matrices) and general language proficiency (PPVT).

Zero-order cross-language correlations for the phonological awareness and language tasks are presented in the upper panel of Table 3. The correlation coefficients on the diagonal indicate the relation between the same tasks in the two languages; the off-diagonal cells are correlations between tasks in one language and different tasks in the other language. Our interest in this study was to determine the extent to which nonlinguistic cognitive ability overlapped with the linguistic measures, and was in part responsible for the correlation in performance across languages. Therefore, scores on the Raven's Matrices and working memory tasks were partialed out of the correlation matrix. The second-order correlation matrix controlling for these scores is reported in the lower panel of Table 3.

Controlling for the nonlinguistic cognitive measures reduced the relatedness between the linguistic tasks in the two languages, indicating that these cognitive abilities contributed in part to the cross-linguistic correlations. It is of importance that the relation between English and Chinese reading was no longer statistically significant when the cognitive measures were partialed out of the analysis. The only surviving correlation between English reading and a Chinese task was with Chinese phoneme onset deletion $(r=.71, p<.01)$, the skill most often cited as predicting English word identification. In contrast, the cross-linguistic correlations between the English and Chinese syllable deletion (medial and final positions) and phoneme onset deletion tasks remained significant after partialing out variance because of the cognitive factors $(r \mathrm{~s}>.42, \mathrm{ss}<.01)$. The correlation between English phoneme onset deletion and Chinese syllable deletion and between English phoneme counting and Chinese phoneme onset deletion also remained strong ( $r \mathrm{~s}>.42, p \mathrm{~s}<.01)$. Whatever is common across languages for these tasks is not captured by the more general ability used to solve the Raven's Matrices and working memory tasks. It was interesting that the syllable onset deletion tasks were not correlated across languages, both before and after taking into account working memory and Raven's Matrices. Syllable onset deletion appears to be different from the other phonological awareness tasks and different as well in each language. In English, this task correlates with phoneme counting, the most analytic of the phonological awareness tasks, indicating a role for phonological analysis in this syllable onset deletion. In contrast, Chinese syllables are salient (Chen \& Yip, 2001) and little segmentation and analysis are required to isolate the initial syllable. Some evidence for this difference is the better performance on the syllable onset deletion task in Chinese than in English, $t(56)=-1.38$, $p<.01$. For Chinese, the correlation was between syllable deletion in the medial position and phoneme onset deletion, the most analytic of the tasks in Chinese. Thus, differences in phonological structure between languages leads to somewhat different processes for solving various phonological awareness tasks and modify as well the correlation between phonological awareness abilities across languages. 
Table 3. Zero-order and second-order cross-language correlations between English and Chinese tasks

\begin{tabular}{|c|c|c|c|c|c|c|c|}
\hline \multirow[b]{2}{*}{ Chinese Task } & \multicolumn{7}{|c|}{ English Task } \\
\hline & 1 & 2 & 3 & 4 & 5 & 6 & 7 \\
\hline \multicolumn{8}{|c|}{ Zero-Order Correlations } \\
\hline 1. PPVT & .09 & -.05 & .09 & .19 & .17 & .11 & .07 \\
\hline 2. Syllable deletion, onset & .23 & .05 & $.42^{* *}$ & .10 & $.40^{* *}$ & .24 & .26 \\
\hline 3. Syllable deletion, medial & .21 & .07 & $.44^{* *}$ & .13 & $.36^{* *}$ & .15 & .30 \\
\hline 4. Syllable deletion, final & .28 & .13 & .04 & $.48^{* *}$ & $.43^{* *}$ & .09 & .19 \\
\hline 5. Phoneme onset deletion & $.42^{* *}$ & .22 & .21 & -.05 & $.64^{* * *}$ & $.43^{* *}$ & $.77^{* * *}$ \\
\hline 6. Tone/phoneme counting & .19 & -.00 & $.37^{* *}$ & .01 & .18 & .06 & $.39 * *$ \\
\hline 7. Word identification & .08 & .21 & .01 & -.05 & $.35^{* *}$ & .24 & $.39^{* *}$ \\
\hline \multicolumn{8}{|c|}{ Second-Order Correlations } \\
\hline 1. PPVT & .05 & -.11 & .07 & .18 & .07 & .09 & -.06 \\
\hline 2. Syllable deletion, onset & .14 & -.00 & $.41^{* *}$ & .05 & .26 & .24 & .10 \\
\hline 3. Syllable deletion, medial & .12 & .02 & $.43^{* *}$ & .08 & .23 & .14 & .16 \\
\hline 4. Syllable deletion, final & .20 & .10 & .01 & $.46^{* *}$ & $.34^{* *}$ & .08 & .04 \\
\hline 5. Phoneme onset deletion & .30 & .21 & .18 & -.17 & $.53 * * *$ & $.47^{* *}$ & $.71^{* * *}$ \\
\hline 6. Tone/phoneme counting & .09 & -.11 & $.37^{* *}$ & -.06 & -.08 & .02 & .21 \\
\hline 7. Word identification & -.01 & .14 & -.03 & -.11 & .20 & .22 & .25 \\
\hline
\end{tabular}

Note: Second-order correlations are controlled for working memory and Raven's Matrices. PPVT, Peabody Picture Vocabulary Test.

$* * p<.01{ }^{* * *} p<.001$. 
Luk \& Bialystok: Phonological awareness and word identification

Table 4. Orthogonal rotated pattern and final communality estimates from principal component analysis

\begin{tabular}{lccc}
\hline \hline \multirow{2}{*}{ Tasks } & \multicolumn{3}{c}{ Component } \\
\cline { 2 - 4 } & $\begin{array}{c}\text { Phonological } \\
\text { Awareness }\end{array}$ & $\begin{array}{c}\text { Verbal } \\
\text { Memory }\end{array}$ & $\begin{array}{c}\text { Phonological } \\
\text { Analysis }\end{array}$ \\
\hline English medial syllable deletion & .83 & -.11 & .05 \\
Chinese & & & .20 \\
$\quad$ Onset syllable deletion & .60 & .20 & .07 \\
$\quad$ Medial syllable deletion & .68 & .13 & -.09 \\
$\quad$ Tone awareness & .68 & .01 & -.05 \\
Final syllable deletion & & & .12 \\
$\quad$ English & .15 & .87 & .83 \\
$\quad$ Chinese & -.04 & .08 & .83 \\
English & -.04 & .08 & .84 \\
$\quad$ Onset syllable deletion & .16 & -.03 & \\
Phoneme counting & &
\end{tabular}

\section{Principal components and regression analyses}

The within-language correlation patterns among tasks indicate that reading in each language is built from a different set of skills. Therefore, to establish the contribution of phonological awareness to each of English and Chinese word identification, principal component analysis and hierarchical regression models were carried out to determine the relationship among the phonological awareness tasks in the two languages and their relation to reading. The principal component analysis, using the principal axis method and a varimax (orthogonal) rotation pattern, included six measures for the syllable deletion tasks (three positions each in two languages), two phoneme onset deletion tasks, English phoneme counting, and Chinese tone awareness. The varimax rotation pattern was chosen because it maximizes the variance of a column of the factor pattern matrix. Because the factors generated from the varimax rotation pattern are assumed to be uncorrelated, a variable that loaded on more than one factor should therefore be dropped from the analysis (Hatcher, 1994). The solution produced three components, but phoneme onset deletion in English and Chinese loaded on two of them. Therefore, an additional analysis was conducted excluding the two phoneme onset deletion tasks. Three components were produced based on eigenvalues greater than 1 and the scree plot confirmed the meaningfulness of the three components. Collectively, the three components accounted for $63 \%$ of the total variance in all the phonological awareness tasks.

Table 4 presents the tasks included in the model and their corresponding factor loadings on the three components. Tasks that had factor loadings equal to or greater than .35 were considered as contributing to that factor. The first factor was identified as general phonological awareness. It included tasks in both languages and was correlated with Raven's Matrices and working memory 
Luk \& Bialystok: Phonological awareness and word identification

( $r \mathrm{~s}>.29, p \mathrm{~s}<.03)$. The second factor was identified as short-term verbal memory and included final syllable deletion in both languages. This factor correlated with working memory $(r=.26, p<.05)$. The third factor was identified as phonological analysis and reflects the ability to deal with the phonological stimuli in a detailed manner. It includes English syllable onset deletion and phoneme counting. Chinese syllable onset deletion does not require the same level of analysis because Chinese syllables are more salient than their English counterparts.

Summary results of two hierarchical regression models predicting English and Chinese word recognition are presented in Table 5. The two cognitive measures, Raven's Matrices and working memory, were entered in the first step, English and Chinese PPVT were entered in the second step, and the three factors obtained from the principal component analysis were entered as the third step. The $R^{2}$ values for the models predicting English and Chinese word recognition were .57 and .31 , respectively $(p s<.01)$. For English reading, the third factor, phonological analysis, remained the only significant predictor after controlling for the cognitive measures and vocabulary. However, none of the principal component factors predicted Chinese word recognition after controlling for cognitive measures and receptive vocabulary. The analysis was repeated using $z$ scores instead of raw scores and the pattern of results was the same.

\section{DISCUSSION}

Bilingual children who were learning to read in English and Cantonese completed a set of cognitive tests and solved phonological awareness and word identification tasks in both languages. The main results were that phonological awareness was strongly related across the two languages even after the variance from nonlinguistic cognitive measures was removed, word identification was not related across languages after general cognitive background factors were controlled, and a different pattern of abilities predicted reading in each language. Therefore, once basic cognitive ability has been accounted for, there is little left that is comparable about early reading in two such different writing systems. In contrast, even after removing individual differences attributable to these cognitive measures, there is still significant commonality in the ability to analyze the phonological structure of different languages, irrespective of the type of language and the system in which it is written. This pattern shows that phonological awareness and reading reflect different cross-language relationships in English-Cantonese bilingual children who are learning to read languages represented by two writing systems. Models that propose more general relationships between phonological awareness and reading must minimally be restricted in terms of the range of languages and writing systems to which they apply.

Consistent with other literature, the correlation between phonological awareness tasks across languages indicates a strong central component for this ability, even for languages that appear to be phonologically diverse (e.g., Anthony \& Lonigan, 2004; Manis, Lindsey, \& Bailey, 2004; Wang et al., 2005; for a review, see Durgunoğlu, 2002). This correlation remained strong even after the variance from some basic cognitive abilities was removed from the analysis. Therefore, the common cognitive basis for these phonological tasks is not captured simply by 
Table 5. Summary of hierarchical regression analysis for predicting English and Chinese word recognition $(N=57)$

\begin{tabular}{|c|c|c|c|c|c|c|c|}
\hline \multicolumn{4}{|c|}{ English Word Recognition } & \multicolumn{4}{|c|}{ Chinese Word Recognition } \\
\hline Variable & B & $S E \mathrm{~B}$ & $\beta$ & Variable & $\mathrm{B}$ & $S E \mathrm{~B}$ & $\beta$ \\
\hline Step 1 & & & & Step 1 & & & \\
\hline Raven's Matrices & 0.88 & 0.46 & .19 & Raven's matrices & 0.39 & 0.21 & .25 \\
\hline Working memory & 0.66 & 0.24 & $.30 * *$ & Working memory & 0.14 & 0.10 & .18 \\
\hline Step 2 & & & & Step 2 & & & \\
\hline English PPVT (std.) & 0.34 & 0.14 & $.24^{*}$ & Chinese PPVT (std.) & 0.12 & 0.05 & $.32^{*}$ \\
\hline Step 3 & & & & Step 3 & & & \\
\hline Phonological awareness & 3.72 & 1.98 & .20 & Phonological awareness & -0.09 & 0.88 & -.01 \\
\hline Verbal memory & -2.64 & 1.85 & -.14 & Verbal memory & -1.35 & 0.84 & -.20 \\
\hline Phonological analysis & 7.25 & 1.81 & $.38^{* * *}$ & Phonological analysis & 1.45 & 0.80 & .22 \\
\hline
\end{tabular}

Note: Step $1 R^{2}=.29$ and $.15(p \mathrm{~s}<.05)$ for English and Chinese readings, respectively; $\Delta R^{2}=.09$ and $.07(p<.01$ and .05$)$ for Step 2 in English and Chinese readings, respectively; $\Delta R^{2}=.18$ and $.08(p<.001$ and $n s)$ for Step 3 in English and Chinese readings, respectively. PPVT, Peabody Picture Vocabulary Test.

${ }^{*} p<.05 .{ }^{* *} p<.01 .{ }^{* * *} p<.001$. 
general fluid intelligence, as assessed by Raven's Matrices or working memory tasks. Moreover, the absence of correlation between PPVT scores and the phonological awareness tasks (with the exception of English phoneme onset deletion) indicates that this common ability is not simple language proficiency. Therefore, the results point to an ability that is responsible for analyzing the phonological structure of language, can be applied equally to any language, and is separate from general cognitive functioning and from specific linguistic competence.

What, then, is this common structure for phonological awareness that is not included in basic cognitive abilities? Previous research has led to conflicting positions on this issue, sometimes reporting a single factor solution (e.g., Anthony \& Lonigan, 2004; Schatchneider et al., 1999) and sometimes a more differentiated construct for phonological awareness (e.g., Wagner, Torgesen, Laughon, Simmins, \& Rashotte, 1993). Part of the contradiction can be traced to the specific tasks used and the method of analysis followed to interpret their organization. For example, Wagner et al. (1993) included phonological measures that focused on cognitive processes such as phonological memory, coding, and retrieval, whereas Schatchneider et al. (1999) investigated tasks that were based on word-level processing such as phoneme blending, isolation, and elision. McBride-Chang (1995) administered a battery of phonological awareness tasks and cognitive tasks to children in third and fourth grades. Her results identified three components of phonological awareness that applied across all the tasks: general cognitive ability, verbal memory, and speech perception.

The principal component analysis in the present study indicates that phonological awareness comprises at least three different factors, similar to those identified in the study by McBride-Chang (1995). Two of the factors, general phonological awareness and phonological analysis, are specific to phonological awareness, and the third, short-term verbal memory, is a more domain-general aspect of fluid intelligence and was related to working memory task in the present study. Nonetheless, these three components cohere into an ability that enables children to analyze the phonological structure of any language, irrespective of the language from which the ability was primarily derived and the structure and writing system of the languages to which it is applied. Moreover, this level of linguistic analysis is differentially invoked when one is learning to read an alphabetic language like English or a morphosyntactic language like Cantonese. Thus, there is strong evidence that phonological awareness is a unique cognitive skill that develops in response to advances in general processing ability and enables the child to perform this analysis on any linguistic input.

The situation is different for word identification in early reading. The profile for word identification in each language was different: it was predicted by different phonological awareness skills and showed no correspondence across languages once the common variance from the cognitive factors had been removed. This pattern indicates that the common basis for early reading in the two languages is built out of some broad cognitive abilities and, once accounted for, leaves little in common for these complex tasks. This result is consistent with earlier research in which there was no correlation between children's early progress in reading English and Chinese, especially once simple cognitive skills had been partialed out (Bialystok, Luk, et al., 2005; Bialystok, McBride-Chang, et al., 2005; Gottardo 
et al., 2001). Nonetheless, the correlation between early reading in two alphabetic languages, such as English and Spanish or English and Hebrew remained strong (Bialystok, Luk, et al., 2005; Geva \& Siegel, 2000). Word identification, therefore, is specific to the demands of a particular language and children must learn, and then relearn each system they encounter. Progress in reading depends on acquiring a set of skills that are specific to the writing system, and possibly specific as well to individual languages that use different orthographic patterns.

This interpretation posits a different cognitive structure for each of phonological awareness and reading. The main cognitive resource necessary for early reading is a general ability for analysis and working memory, but these skills explain only a small portion of the variance and once accounted for, there is little left that is common in learning to read in English and in Chinese. The main cognitive resource necessary for early phonological awareness is a specific ability for phonological analysis that can be applied equally to any language. It is independent of the general abilities captured by Raven's Matrices and working memory, and separate as well from the general cognitive skills required for early alphabetic reading.

It follows from this view that the relationship between phonological awareness and reading will depend on the demands created by individual writing systems. To the extent that reading shares the need for phonological analysis that is assessed in most phonological awareness tasks, the two abilities will be related. However, it is misleading to claim that phonological awareness (in general) is causally responsible for reading (in general), as cautioned by Castles and Coltheart (2004; but also see Hulme, Caravolas, Málkova, \& Briqstocke, 2005; Hulme, Snowling, Caravolas, \& Carroll, 2005, for comments). Rather, overlapping demands between types of reading and aspects of phonological analysis will produce a closer relationship between these developing skills. Further, because phonological awareness can develop through any language and generalize to another, it may indeed be causally implicated in learning to read in a new language or writing system once it has been established through an earlier language.

This point can be illustrated by a study by Leong, Cheng, and Tan (2005), in which children from Hong Kong and Beijing were compared on pseudoword reading in both Chinese and English. The relationship between phonological awareness and Chinese pseudoword reading was strong for Beijing children but not for Hong Kong children, but the relationship with English pseudoword reading was strong for both groups. The children in Beijing had learned pinyin, a phonetic transcription of Chinese, so for them, both Chinese and English shared a need for phonetic analysis. For children in Hong Kong who had not learned pinyin, there was no role for phonological analysis in reading Chinese. This example shows the limitation of considering phonological awareness as a predictor of reading, even in cases where the language is essentially the same, namely Chinese, but children's experience in learning to read was different.

Corroboration for the view presented here comes from two recent meta-analyses of imaging studies. In the first, Tan, Laird, Li, and Fox (2005) found both overlapping and distinct cortical areas involved in the phonological processing of alphabetic and character languages, indicating a pattern based on both common and unique processing for each. Tan et al. (2005) suggest that language representations, phonology, and cognitive processes are interdependent, and influence 
Luk \& Bialystok: Phonological awareness and word identification

the development of functional neuroanatomy. In the second, Bolger, Perfetti, and Schneider (2005) conducted a meta-analysis of word-reading neuroimaging studies and found that the left middle fusiform gyrus is the main localization area for visual word recognition. However, character and alphabetic languages have different foci within the proximity of the left middle fusiform gyrus. Again, the functional neuroanatomy of language processing and reading is a consequence of the interaction between the cognitive processes involved in word identification and the written representations of languages. Reading in different writing systems leads to different cortical consequences.

The results of the present study show that bilingual children's early reading in two disparate languages is constructed from knowledge and processes specific to each writing system. There is little evidence of generalization of ability across languages once the common individual variation from cognitive level has been taken into account. Contrary to some beliefs, reading is not simply "reading," and specific knowledge and instruction is necessary for children to gain competence in systems that rely on different foundations and assumptions.

Most of the previous research reporting strong cross-language correspondences in reading for young readers has either been based on bilingual children learning to read in two similar writing systems (usually alphabetic) or failed to account for the common variance of cognitive ability, creating the illusion of correlation by means of an underlying factor. The present results make the distinction between two separate bases of reading in different systems more clear. The main conclusion is that bilingual children learning to read in two different writing systems transfer phonological awareness skills irrespective of the different written representations but need to develop individual reading skills. The pattern of results from the present study describe the abilities of children who are equally proficient in spoken Cantonese and English but have had more literacy experience in English; these results should be extended to children whose formal literacy instruction in both languages is also more comparable to address the influence of degree of instruction on developmental trajectories for reading in bilingual children. Finally, future studies should extend these findings and examine if the cross-language relationships in phonological awareness and reading change in bilingual children during their early literacy acquisition period.

\section{REFERENCES}

Anthony, J. L., \& Lonigan, C. J. (2004). The nature of phonological awareness: Converging evidence from four studies of preschool and early grade school children. Journal of Educational Psychology, 96, 43-55.

Bialystok, E., Craik, F. I. M., Klein, R., \& Viswanathan, M. (2004). Bilingualism, aging, and cognitive control: Evidence from the Simon task. Psychology and Aging, 19, 290-303.

Bialystok, E., Luk, G., \& Kwan, E. (2005). Bilingualism, biliteracy, and learning to read: Interactions among languages and writing systems. Scientific Studies of Reading, 9, 43-61.

Bialystok, E., McBride-Chang, C., \& Luk, G. (2005). Bilingualism, language proficiency, and learning to read in two writing systems. Journal of Educational Psychology, 97, 580-590.

Bolger, D. J., Perfetti, C. A., \& Schneider, W. (2005). Cross-cultural effect on the brain revisited: Universal structures plus writing system variation. Human Brain Mapping, 25, 92-104.

Branum-Martin, L., Mehta, P. D., Fletcher, J. M., Carlson, C. D., Ortiz, A., Carlo, M., et al. (2006). Bilingual phonological awareness: Multilevel construct validation among Spanish-speaking 
Luk \& Bialystok: Phonological awareness and word identification

kindergarteners in transitional bilingual education classrooms. Journal of Educational Psychology, 98, 170-181.

Cain, K., Oakhill, J., \& Bryant, P. (2004). Children's reading comprehension ability: Concurrent prediction by working memory, verbal ability, and component skills. Journal of Educational Psychology, 96, 31-42.

Castles, A., \& Coltheart, M. (2004). Is there a causal link from phonological awareness to success in learning to read? Cognition, 91, 77-111.

Chan, C. K. K., \& Siegel, L. S. (2001). Phonological processing in reading Chinese among normally achieving and poor readers. Journal of Experimental Child Psychology, 80, 23-43.

Chen, H.-C., \& Yip, M. C. W. (2001). Processing syllabic and sub-syllabic information in Cantonese. Journal of Psychology in Chinese Societies, 2, 199-210.

Cormier, P., \& Dea, S. (1997). Distinctive patterns of relationship of phonological awareness and working memory with reading development. Reading and Writing, 9, 193-206.

Coulmas, F. (1989). The writing systems of the world. Oxford: Basil Blackwell.

DeFrancis, J. (1989). Visible speech: The diverse oneness of writing systems. Honolulu, HI: University of Hawaii Press.

Dunn, L. M., \& Dunn, L. M. (1997). Peabody Picture Vocabulary Test (3rd ed.). Circle Pines, MN: American Guidance Service.

Durgunoğlu, A. Y. (2002). Cross-linguistic transfer in literacy development and implications for language learners. Annals of Dyslexia, 52, 189-204.

Durgunoğlu, A. Y., Nagy, W. E., \& Hancin-Bhatt, B. J. (1993). Cross-language transfer of phonological awareness. Journal of Educational Psychology, 85, 453-465.

Foy, J. G., \& Mann, V. (2001). Does strength of phonological representations predict phonological awareness in preschool children? Applied Psycholinguistics, 22, 301-325.

Gathercole, S. E., \& Baddeley, A. D. (1989). Evaluation of the role of phonological STM in the development of vocabulary in children: A longitudinal study. Journal of Memory and Language, 28, 200-213.

Gathercole, S. E., Willis, C. S., Emslie, H., \& Baddeley, A. D. (1992). Phonological memory and vocabulary development during the early school years: A longitudinal study. Developmental Psychology, 28, 887-898.

Geva, E., \& Siegel, L. S. (2000). Orthographic and cognitive factors in the concurrent development of basic reading skills in two languages. Reading and Writing: An Interdisciplinary Journal, 12, 1-30.

Gholamain, M., \& Geva, E. (1999). Orthographic and cognitive factors in the concurrent development of basic reading skills in English and Persian. Language Learning, 49, 183-217.

Gomez, C., \& Reason, R. (2002). Cross-linguistic transfer of phonological skills: A Malaysian perspective. Dyslexia, 8, 22-33.

Goswami, U. C., \& Bryant, P. (1990). Phonological skills and learning to read. London: Erlbaum.

Gottardo, A., Siegel, L. S., Yan, B., \& Wade-Woolley, L. (2001). Factors related to English reading performance in children with Chinese as a first language: More evidence of crosslanguage transfer of phonological processing. Journal of Educational Psychology, 93, 530542.

Hanley, J. R., Tzeng, O., \& Huang, H. S. (1999). Learning to read Chinese. In M. Harris \& G. Hatano (Eds.), Learning to read and write: A cross-linguistic perspective (pp. 173-195). New York: Cambridge University Press.

Hatcher, L. (1994). A step-by-step approach to using the $S A S^{\circledR}$ system for factor analysis and structural equation modeling. Cary, NC: SAS Institute.

Ho, C. S.-H., \& Bryant, P. (1997a). Learning to read Chinese beyond the logographic phase. Reading Research Quarterly, 32, 276-289.

Ho, C. S.-H., \& Bryant, P. (1997b). Phonological skills are important in learning to read Chinese. Developmental Psychology, 33, 946-951.

Hu, C. F., \& Catts, H. W. (1998). The role of phonological processing in early reading ability: What we can learn from Chinese. Scientific Studies of Reading, 2, 55-79.

Huang, H. S., \& Hanley, J. R. (1995). Phonological awareness and visual skills in learning to read Chinese and English. Cognition, 54, 73-98.

Hulme, C., Caravolas, M., Málkova, G., \& Briqstocke, S. (2005). Phoneme isolation ability is not simply a consequence of letter-sound knowledge. Cognition, 97, B1-B11. 
Luk \& Bialystok: Phonological awareness and word identification

Hulme, C., Snowling, M., Caravolas, M., \& Carroll, J. (2005). Phonological skills are (probably) one cause of success in learning to read: A comment on Castles and Coltheart. Scientific Studies of Reading, 9, 351-365.

Kirby, J. R., Parrila, R. K., \& Pfeiffer, S. L. (2003). Naming speed and phonological awareness as predictors of reading development. Journal of Educational Psychology, 95, 453-464.

Leong, C. K., Cheng, P. W., \& Tan, L.-H. (2005). The role of sensitivity to rhymes, phonemes and tones in reading English and Chinese pseudowords. Reading and Writing, 18, 1-26.

Manis, F. R., Lindsey, K. A., \& Bailey, C. E. (2004). Development of reading in grades K-2 in Spanish-speaking English-language learners. Learning Disabilities Research and Practice, 19, 214-224.

McBride-Chang, C. (1995). What is phonological awareness? Journal of Educational Psychology, 87, $179-192$.

McBride-Chang, C., Bialystok, B., Chong, K. K. Y., \& Li, Y. (2004). Levels of phonological awareness in three cultures. Journal of Experimental Child Psychology, 89, 93-111.

McBride-Chang, C., \& Ho, C. S. (2000). Developmental issues in Chinese children's character acquisition. Journal of Educational Psychology, 92, 50-55.

McBride-Chang, C., \& Kail, R. V. (2002). Cross-cultural similarities in the predictors of reading acquisition. Child Development, 73, 1392-1407.

Metsala, J. L. (1999). Young children's phonological awareness and nonword repetition as a function of vocabulary development. Journal of Educational Psychology, 91, 3-19.

Muter, V., \& Snowling, M. (1998). Concurrent and longitudinal predictors of reading: The role of metalinguistic and short-term memory skills. Reading Research Quarterly, 33, 320337.

Nation, K., \& Snowling, M. J. (2004). Beyond phonological skills: Broader language skills contribute to the development of reading. Journal of Research in Reading, 27, 342-356.

Oakhill, J. V., Cain, K., \& Bryant, P. E. (2003). The dissociation of word reading and text comprehension: Evidence from component skills. Language and Cognitive Processes, 18, 443468.

Oakhill, J., \& Kyle, F. (2000). The relation between phonological awareness and working memory. Journal of Experimental Child Psychology, 75, 152-164.

Passenger, T., Stuart, M., \& Terrell, C. (2000). Phonological processing and early literacy. Journal of Research in Reading, 23, 55-66.

Perfetti, C. A. (2003). The universal grammar of reading. Scientific Studies of Reading, 7, 3-24.

Raven, J. C. (1998). Raven's Coloured Progressive Matrices. San Antonio, TX: Psychological Corporation.

Rohl, M., \& Pratt, C. (1995). Phonological awareness, verbal working memory and the acquisition of literacy. Reading and Writing, 7, 327-360.

Savage, R., \& Stuart, M. (2001). Orthographic analogies and early reading: Exploration of performance and variation in two transfer tasks. Reading and Writing: An Interdisciplinary Journal, 14, 571598.

Schatschneider, C., Francis, C. J., Foorman, B. R., Fletcher, J. M., \& Mehta, P. (1999). The dimensionality of phonological awareness: An application of item response theory. Journal of Educational Psychology, 91, 439-449.

Siok, W. T., \& Fletcher, P. (2001). The role of phonological awareness and visual-orthographic skills in Chinese reading acquisition. Developmental Psychology, 37, 886-699.

Siok, W. T., Perfetti, C. A., Jin, Z., \& Tan, L. H. (2004). Biological abnormality of impaired reading is constrained by culture. Nature, 431, 71-76.

Swanson, H. L., Sáez, L., Gerber, M., \& Leafstedt, J. (2004). Literacy and cognitive functioning in bilingual and nonbilingual children at or not at risk for reading disabilities. Journal of Educational Psychology, 96, 3-18.

Tan, L. H., Laird, A. R., Li, K., \& Fox, P. T. (2005). Neuroanatomical correlates of phonological processing of Chinese characters and alphabetic words: A meta-analysis. Human Brain Mapping, 25, 83-91.

Wade-Woolley, L., \& Geva, E. (2000). Processing novel phonemic contrasts in the acquisition of L2 word reading. Scientific Studies of Reading, 4, 295-311.

Wagner, R. K., \& McBride-Chang, C. (1996). The development of reading-related phonological processing abilities. Annals of Child Development, 12, 177-206. 
Luk \& Bialystok: Phonological awareness and word identification

Wagner, R. K., Torgesen, J. K., Laughon, P., Simmins, K., \& Rashotte, C. (1993). Development of young readers' phonological processing abilities. Journal of Educational Psychology, 85, 83-103.

Wang, M., Cheng, C. X., \& Chen, S. W. (2006). Contribution of morphological awareness to ChineseEnglish biliteracy acquisition. Journal of Educational Psychology, 98, 542-553.

Wang, M., Park, Y., \& Lee, K. R. (2006). Korean-English biliteracy acquisition: Cross-language phonological and orthographic transfer. Journal of Educational Psychology, 98, 148-158.

Wang, M., Perfetti, C. A., \& Liu, Y. (2005). Chinese-English biliteracy acquisition: Cross-language and writing system transfer. Cognition, 97, 67-88.

Wayland, R. P., \& Guion, S. G. (2004). Training English and Chinese listeners to perceive Thai tones: A preliminary report. Language Learning, 54, 681-712.

Woodcock, R. W., \& Johnson, M. B. (1987). Woodcock-Johnson Psycho-Educational Battery. Riverside, CA: DLM Teaching Resources. 